\title{
JS-K, a glutathione/glutathione S-transferase- activated nitric oxide releasing prodrug inhibits androgen receptor and WNT-signaling in prostate cancer cells
}

Martin Laschak ${ }^{1}$, Klaus-Dieter Spindler ${ }^{1}$, Andres J Schrader ${ }^{2}$, Andrea Hessenauer ${ }^{1}$, Wolfgang Streicher ${ }^{1,2}$, Mark Schrader ${ }^{2}$ and Marcus V Cronauer ${ }^{2^{*}}$

\begin{abstract}
Background: Nitric oxide (NO) and its oxidative reaction products have been repeatedly shown to block steroid receptor function via nitrosation of zinc finger structures in the DNA-binding domain (DBD). In consequence NOdonors could be of special interest for the treatment of deregulated androgen receptor(AR)-signaling in castration resistant prostate cancer (CRPC).

Methods: Prostate cancer (PCa) cells were treated with JS-K, a diazeniumdiolate derivate capable of generating large amounts of intracellular NO following activation by glutathione S-transferase. Generation of NO was determined indirectly by the detection of nitrate in tissue culture medium or by immunodetection of nitrotyrosine in the cytoplasm. Effects of JS-K on intracellular AR-levels were determined by western blotting. AR-dimerization was analyzed by mammalian two hybrid assay, nuclear translocation of the AR was visualized in PCa cells transfected with a green fluorescent AR-Eos fusion protein using fluorescence microscopy. Modulation of AR- and WNT-signalling by JS-K was investigated using reporter gene assays. Tumor cell proliferation following JS-K treatment was measured by MTT-Assay.

Results: The NO-releasing compound JS-K was shown to inhibit AR-mediated reporter gene activity in 22Rv1 CRPC cells. Inhibition of AR signaling was neither due to an inhibition of nuclear import nor to a reduction in ARdimerization. In contrast to previously tested NO-donors, JS-K was able to reduce the intracellular concentration of functional AR. This could be attributed to the generation of extremely high intracellular levels of the free radical $\mathrm{NO}$ as demonstrated indirectly by high levels of nitrotyrosine in JS-K treated cells. Moreover, JS-K diminished WNTsignaling in AR-positive 22Rv1 cells. In line with these observations, castration resistant 22Rv1 cells were found to be more susceptible to the growth inhibitory effects of JS-K than the androgen dependent LNCaP which do not exhibit an active WNT-signaling pathway.
\end{abstract}

Conclusions: Our results suggest that small molecules able to inhibit WNT- and AR-signaling via NO-release represent a promising platform for the development of new compounds for the treatment of CRPC.

\section{Background}

Nitric oxide (NO), a free radical gas, is a pleiotropic molecule critical to a number of physiological and pathological processes. NO-releasing drugs are a growing class of promising new therapeutics with applications in a

\footnotetext{
* Correspondence: marcus.cronauer@uni-ulm.de

2Department of Urology, Ulm University, Prittwitzstrasse 43, 89075, Ulm, Germany

Full list of author information is available at the end of the article
}

large variety of diseases like cardiovascular and respiratory disorders, osteoporosis, Alzheimer's disease, inflammatory lesions and urinary incontinence [1-4]. Moreover there is increasing evidence that NO donors could have potential in the prevention and therapy of various malignant tumors like myeloma, breast cancer, ovarian cancer, pancreatic cancer or prostate cancer (PCa) [5-11].

$\mathrm{PCa}$ is the most commonly diagnosed neoplasm in elderly men and the second cause of cancer related

\section{Biomed Central}


deaths in the Western world [12]. Current treatment for advanced $\mathrm{PCa}$ is mainly based on androgen ablation therapies like orchiectomy, systemic administration of LHRH analog/blocker or anti-androgens. Unfortunately, the benefit of androgen ablation is only transitory. Within a few years many PCa progress to a state of the disease termed castration resistant prostate cancer (CPRC) where tumor cells grow and survive under subphysiological levels of androgens [13]. Although in vitro the development of a castration resistant phenotype is mostly based on the loss of the AR in PCa cells, several clinical studies demonstrated that the AR is rarely lost in CRPC cells in vivo [14-16]. Indeed, CRPC cells continue to depend on AR-signalling but bypass the requirements for physiological levels of circulating androgens. Various molecular mechanisms that promote AR-dependent growth of CRPC cells growing under androgen deprived conditions have been identified: overexpression/amplification of the AR (hypersensitive pathway), AR mutations that broaden ligand specificity (promiscious pathway), AR-activation by non steroid ligands like growth factors or cytokines (outlaw pathway) [17] as well as the expression of C-terminally truncated AR variants lacking vast parts of the ligand binding domain (LBD). These AR-variants, termed AR $\triangle \mathrm{LBD}$, are either products of alternative splicing (AR-V), point mutations leading to premature stop codons or proteolytic cleavage of the AR protein [18-21]. In contrast to a full length AR which is activated upon androgenic stimuli, previous in vitro studies were able to show that most AR $\triangle$ LBDs, devoid of a ligand binding domain, are constitutively active [18-21]. As AR $\Delta$ LBDs lack most parts of the LBD situated in the C-terminus of the AR, they are insensitive to any form of androgen ablation.

Nitric oxide (NO) and its oxidative reaction products have been repeatedly shown to block nuclear receptors via nitrosation of their zinc finger structures in the DNAbinding domain (DBD). The DBD is an essential part of functional full length $A R$ as well as the constitutively active ARALBDs. In consequence NO-donors could be of special interest for the treatment of deregulated ARsignalling in CRPC cells. Inhibition of AR-functions following treatment with the long living spontaneous NOdonor (Z)-1-[N-(2-Aminoethyl)-N-(2-ammonioethyl) amino]diazen-1-ium-1,2-diolat (DETA/NO) has recently been demonstrated [22]. However, due to the short halflife of the free radical NO in cell culture medium, relatively high concentrations of DETA/NO were necessary to induce effects on intracellular nuclear receptors. In order to generate large amounts of intracellular NO, new compounds, able to deliver NO in a spatially controllable manner, are needed. In our study we used the non-ionic, nitroaromatic diazeniumdiolate JS-K, a glutathione Stransferase(GST)-activated NO-prodrug able to generate high intracellular levels of $\mathrm{NO}$ in the micromolar range $[23,24]$.

Studying the effects of JS-K on AR- and WNT-signalling in the AR-positive PCa cell lines 22Rv1 and LNCaP we were able to demonstrate that only a 100 -fold lower concentration of the GST-activated JS-K are necessary to reach comparable biological effects in $\mathrm{PCa}$ cells than the commonly used DETA/NO that spontaneously generates $\mathrm{NO}$ in physiological fluids. Our data show that NOprodrugs, capable of generating large intracellular amounts of $\mathrm{NO}$, may be suitable for the treatment of advanced prostate cancer.

\section{Methods}

Plasmids, antibodies, chemicals

Probasin promoter driven luciferase-reporter plasmid (pGL3E-Probasin) was kindly provided by Prof. Dr. Z. Culig (Innsbruck, Austria). The pARt1EosFP expression plasmid coding for a green fluorescent AR-Eos fusion protein (AR-EosFP) was a gift from Prof. F. Oswald (Ulm, Germany). The CMV-promoter driven $\beta$-catenin expression plasmid pbCAT, containing human $\beta$-catenin cDNA with an activating S33Y mutation was provided by Dr. H. Clevers (Utrecht, The Netherlands). TCFreporter plasmids pTopFlash (TOP) and pFopFlash (FOP), containing three copies of wild-type or mutant TCF-binding sites upstream of a thymidine kinase minimal promoter driving a luciferase gene, were purchased from Upstate Biotechnology (Lake Placid, NY, USA). Renilla reniformis luciferase reporter plasmid pRL-tkLUC was a product of Promega (Mannheim, Germany). Mouse monoclonal antibodies directed against beta actin (ab8224) and nitrotyrosine (ab7048) were products of Abcam (Cambridge, UK). Mouse monoclonal antibody AR441 directed against the N-terminus of the AR was purchased from Dako (Hamburg, Germany). The NO-donors O2-(2,4-Dinitrophenyl)-1-[(4-ethoxycarbonyl)piperazin-1-yl]diazen-1-ium-1,2-diolate (JS-K), (Z)-1[N-(2-Aminoethyl)-N-(2-ammonioethyl)amino] diazen-1ium-1,2-diolate (DETA/NO) and the androgen dihydrotestosterone (DHT) were a products of Sigma Aldrich (Taufkirchen, Germany).

\section{Cell culture}

22Rv1, LNCaP, DU-145 and PC-3 cells were purchased from the American Type Culture Collection (Manassas, VA, USA). LNCaP-SSR, a castration resistant LNCaP subline [25,26], was a generous gift from Prof. Martin Burchardt, Greifswald, Germany. 22Rv1, LNCaP, DU-145 and PC-3 were grown in RPMI-1640 (PAA Laboratories GmbH, Pasching, Austria) supplemented with 10\% fetal bovine serum (FBS) and 1\% Penicillin/Streptomycin (BioWest, Nuaille, France). LNCaP-SSR were routinely grown in RPMI-1640, 1\% Penicillin/Streptomycin supplemented 
with $10 \%$ steroid free, dextran charcoal treated FBS (FBSdcc, BioWest, Nuaille, France) [26].

\section{Transfection and reporter gene assays}

22Rv1 cells were grown on 24-well plates (Sarstedt, Nümbrecht, Germany). Transfections were performed using FuGene HD transfection reagent (Roche Diagnostics, Mannheim, Germany) according to the manufacturer's instructions. AR- and WNT-specific reporter gene assays were performed as recently described [22,27]. In brief: (1) ARsignalling: Cells were transfected with $200 \mathrm{ng} /$ well of the AR-dependent reporter-plasmid pGL3E-Probasin. The pRL-tk-LUC vector coding for a Renilla luciferase under control of a constitutively active thymidine kinase promoter was co-transfected ( $80 \mathrm{ng} /$ well) to correct for transfection efficiency. After transfection cells were grown in RPMI 1640 with 5\% dextran charcoal treated steroid free, dextran charcoal treated FBS (FBSdcc; Biowest, Nuaillé, France) and treated with $5 \mathrm{nM}$ DHT and different concentrations of JS-K. (2) WNT-signalling: Luciferase reporter plasmids pTopFlash (250 ng/well) and pFopFlash (250 ng/ well) were mixed either with pbCAT expression vector (250 ng/well) or insert-free vector (250 ng/well). pRL-tkluc (80 ng/well) was co-transfected to correct for transfection efficiency. After an incubation period of $12 \mathrm{~h}$ in RPMI-1640 with 5\% FBSdcc, medium was changed to RPMI-1640 containing 2.5\% FBSdcc with increasing concentrations of JS-K.

AR- and WNT-reporter activities were analyzed after 24 hours using the Dual Luciferase Reporter Assay System (Promega, Mannheim, Germany). Experiments were repeated at least three times and performed in triplicates, unless stated otherwise.

\section{Mammalian two hybrid assay}

To investigate the dimerization of the AR we used the CheckMate/FlexiVector Mammalian Two-Hybrid System from Promega (Mannheim, Germany). VP16 activation domain (pFN10A-AR) and Gal4 DNA binding domain tagged androgen receptor fusion constructs (pFN11A-AR) were cloned according to the supplier's suggestions by using pSG5-AR as template. DU-145 and PC-3 cells were grown in 24-well plates and co-transfected with $150 \mathrm{ng} /$ well of pFN10A-AR, pFN11A-AR and the Gal4 reporter construct pGL4.31. After transfection, cells were cultured and luciferase activities were determined as recently described [28].

\section{Nuclear Translocation assay}

Nuclear translocation of the AR was analyzed in AR-negative DU-145 and PC-3 cells transfected with the green fluorescent AR-EosFP [22,29]. Therefore, prostate cancer cells were transfected in a 24-well plate with pAR-t1EosFP $(0.25 \mu \mathrm{g} /$ well $)$ for 4 hours in RPMI and allowed to grow for another 24 hours in RPMI 1640 supplemented with 5\% FBSdcc and antibiotics. Thereafter, cells were grown in RPMI supplemented with 2.5\% FBSdcc in the presence/ absence of $5 \mathrm{nM}$ DHT and JS-K for 6 hours. Localization of the AR-fusion protein was subsequently analyzed by fluorescence microscopy.

\section{Western Blot analysis}

Proteins were extracted from cells using RIPA buffer as recently described [30]. Proteins (15 $\mu$ g lysate) were separated by Sodium dodecyl sulfate polyacrylamide gel electrophoresis (SDS-Page). Subsequently proteins were transferred onto a nitrocellulose membrane (BioTraceNT, Pall Life Sciences, Dreieich, Germany) by tank blotting (transfer buffer: $20 \mathrm{mM}$ Tris/HCl, $\mathrm{pH}$ 8.7, $150 \mathrm{mM}$ glycine and $20 \%(\mathrm{v} / \mathrm{v})$ methanol). Membranes were blocked in phosphate buffered saline with $0.1 \%$ Tween 20 (v/v) (PBS$\mathrm{T})$ and 5\% BSA (w/v) for 1 hour at room temperature. The membrane was incubated with the primary antibody in PBS-T with $1 \%$ BSA over night at $4^{\circ} \mathrm{C}$. All primary antibodies were used in a dilution of 1:1000, with the exception of the beta-actin antibody, which was diluted 1:20000. The membrane was washed with PBS-T three times before incubating with the peroxidase-coupled secondary antibody in a dilution of 1:2000 in PBS-T with 1\% BSA. Signals were visualized by the SuperSignal West Pico Chemiluminescent Substrate from Pierce (Rockford, USA).

\section{Determination of NO}

$\mathrm{NO}$ was determined indirectly by the photometric measurement of nitrite according to Green et al. [31]

\section{Immunocytochemistry}

For immunocytochemistry 22Rv1 cells were cultured on glass coverslips (BD Falcon Culture Slides, BD Biosciences) washed $(2 \times 5 \mathrm{~min})$ with PBS and fixed with $3.7 \%$ paraformaldehyd for $15 \mathrm{~min}$ at room temperature, washed $(3 \times 10 \mathrm{~min})$ in PBS and permeabilized in $0.2 \%$ Triton X-100 with 1\% BSA in PBS for 5 min at room temperature. The cells were washed $(3 \times 10 \mathrm{~min})$ with PBS containing 1\% BSA. Cells were then incubated with the monoclonal anti-tyrosine antibody (1:25 in PBS, $1 \%$ BSA for $30 \mathrm{~min}$ at $37^{\circ} \mathrm{C}$, washed $(3 \times 10 \mathrm{~min}$ and incubated with the mouse monoclonal anti-goat antibody labeled with Alexa Fluor 488 (Invitrogen, Karlsruhe, Germany, $1: 100)$ for $30 \mathrm{~min}$ at $37^{\circ} \mathrm{C}$. Cells were then washed $(3 \times 10 \mathrm{~min})$, the nuclei stained with DAPI $(2.5 \mu \mathrm{g} / \mathrm{ml}$ in PBS) for $15 \mathrm{~min}$, washed $(3 \times 10 \mathrm{~min})$ and embedded with glycine and polyvinyle alcohol 4-88 (Fluka Analytical, Deisenhofen, Germany).

\section{Cell viability}

Cell viability was determined by means of a colorimetric MTT-assay measuring the reduction of the water 
soluble tetrazolium bromide into its insoluble formazan derivative by functional mitochondria $[32,33]$.

\section{Statistical Analysis}

Data are reported as means \pm standard deviation. Analysis was performed with Student's T-test (two tailed for independent samples) with $\mathrm{p}<0.05$ considered as significant.

\section{Results}

JS-K induces nitrosation of tyrosine residues in cellular proteins

In a previous paper $\mathrm{NO}$ generated by DETA/NO was shown to nitrosate tyrosine residues in proteins to nitrotyrosine [22]. Therefore, we tested JS-K's ability to nitrosate proteins via intracellular NO-release. In order to generate a control substance without the NO-releasing moiety, we took advantage of the observation that sera of patients were repeatedly shown to possess low GST-activity $[34,35]$. In our experiment $5 \mu \mathrm{M}$ JS-K was incubated at $37^{\circ} \mathrm{C}$ in RPMI-1640 supplemented with $10 \%$ FBS. Generation of NO in the medium was measured indirectly by the determination of nitrite. Under these conditions maximal medium nitrite levels were detectable after nine to twelve hours (Figure 1A). The remaining inactive JS-K metabolites S-(2, 4-Dinitrophenyl)-glutathione and 4-carboxy-piperazine [23] were subsequently used as a negative control and termed JS-K

Incubation with $2 \mu \mathrm{M}$ JS-K as well as $200 \mu \mathrm{M}$ DETA/ $\mathrm{NO}$ (serving as positive control) led to a nitrosation of intracellular proteins as shown by fluorescescence microscopy of nitrotyrosine residues (Figure 1B). In contrast, neither untreated cells nor cells treated with the control solution JS- $\mathrm{K}_{\text {neg }}$ harbouring the inactive JS-K metabolites, showed any nitrotyrosine staining (Figure 1B).

\section{JS-K inhibits AR-mediated genomic function in 22Rv1 cells}

To test whether JS-K influences the transcriptional activity of the AR, we transiently co-transfected ARpositive 22Rv1 human prostate cancer cells with pGL3E-Pro, an androgen-responsive probasin-promoter driven reporter plasmid, and pRL-tk-Luc, a Renilla luciferase plasmid under control of a constitutively active thymidine kinase promoter (control of transfection efficiency). Subsequently cells were incubated for 44 hours with $5 \mathrm{nM}$ DHT and increasing concentrations of JS-K

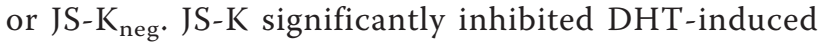
AR-transactivation in a dose-dependent manner. Inhibition was already significant at a concentration of $2 \mu \mathrm{M}$ JS-K. In contrast, JS-K $K_{\text {neg }}$ was unable to diminish AR transcriptional activity even at higher concentrations (Figure 2).
A.

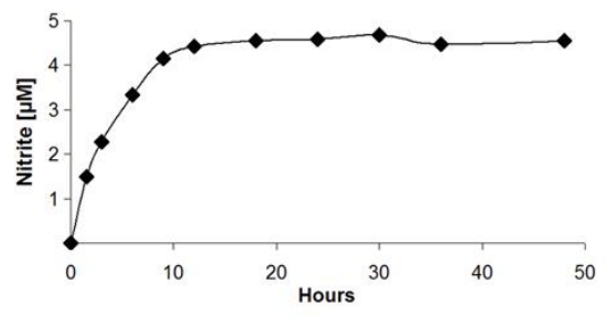

B.
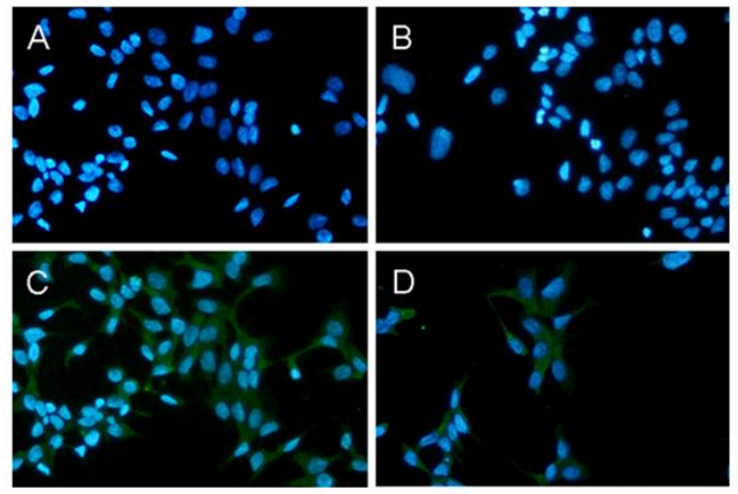

Figure 1 Release of NO from JS-K. (A) Generation of NO from JS$\mathrm{K}$ in RPMl-1640 medium containing 10\% fetal bovine serum was determined indirectly by photorimetric detection of nitrite according to Green et al. [31]. (B) Detection of nitrotyrosine by fluorescence microscopy in 22Rv1 cells: Generation of intracellular NO was detected indirectly by detection of nitrotyrosine (green). Cell nuclei were stained with DAPI. [A] untreated cells, [B] 2 $\mu \mathrm{M}$ JS$K_{\text {neg, }}$ [C] $2 \mu \mathrm{M}$ JS-K, [D] $200 \mu \mathrm{M}$ DETA/NO.

\section{JS-K does not modulate dimerization or nuclear} localization of the AR

In vitro NO has been shown to repress vitamin D3 signalling through inhibition of vitamin D receptor (VDR) - retinoic X receptor (RXR)-heterodimerization [36]. To test whether JS-K can inhibit AR-homodimer formation in vivo, we performed an AR-specific mammalian two hybrid (M2H)-assay in AR-negative PC-3 and DU-145 cells (Figure 3, Additional File 1). As seen in Figure 3, JS-K was unable to repress DHT-induced AR-homodimerization at concentrations that were already sufficient to inhibit AR-transactivation (Figures 3 and 2).

In order to test whether high $\mathrm{NO}$ concentrations are able to influence the nuclear translocation of the AR, we transfected the AR-negative PC-3 with a construct coding for a green fluorescent AR-Eos fusion protein (AR-EosFP) $[22,37]$. Subsequently cells were grown for six hours in the presence/absence of $5 \mathrm{nM}$ DHT with or without JS-K or JS-K $K_{n e g}$. Under hormone-free conditions the AR was predominantly located in the cytoplasm (> 80\%) whereas in presence of DHT the AR was transported to the nucleus 


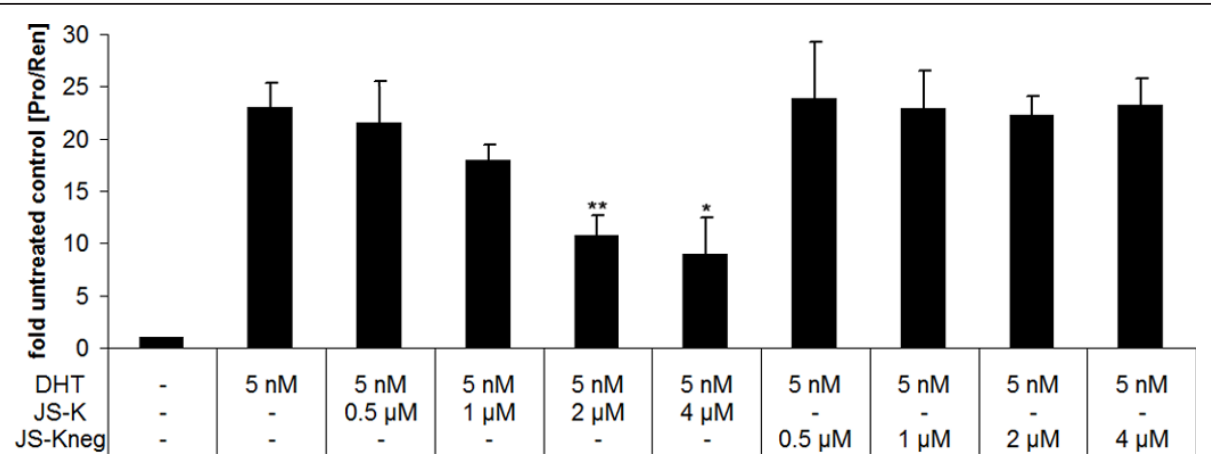

Figure 2 JS-K inhibits AR-dependent reportergene activity in 22Rv1 cells. Cells were cotransfected with a probasin reporter gene plasmid and a Renilla luciferase plasmid serving as transfection control. Subsequently cells were grown in presence/absence of $5 \mathrm{nM}$ DHT. Reportergene activity was determined using the Dual Luciferase Assay System from Promega. Data are presented as fold of untreated controls \pm standard deviation (SD). Results are mean values of three independent experiments performed in quadruplicates: ${ }^{*} p<0.05 ;{ }^{* *} p<0.01$.

(Figure 4). As seen in Figure 4 addition of JS-K (final concentration $4 \mu \mathrm{M}$ ) was unable to reverse the nuclear localization of the AR in DHT treated PC-3 cells $(82 \% \pm 2 \%$ to $78 \pm 2 \%)$. In a complementary experiment transfection of AR negative DU-145 cells with AR-EosFP yielded similar results (Additional File 2).

\section{JS-K leads to a down-regulation of the AR-protein}

In contrast to the commonly used spontaneous NO-donor DETA/NO which generates NO in aquaeous solutions, JS-K is able to generate high amounts of NO within target cells after enzymatic activation by GST. The profound differences in local NO-production prompted us to analyze the effects of JS-K on the AR-concentration in the prostate cancer line 22Rv1 and LNCaP. Both cell lines express functional AR-proteins. Whereas $22 \mathrm{Rv} 1$ cells express a $120 \mathrm{kDa}$ AR-isoform as well as a C-terminally truncated, constitutively active $79 \mathrm{kDa}$ AR-V splicing variant [38] the LNCaP cells express a full length AR $(119 \mathrm{kDa})$ with a

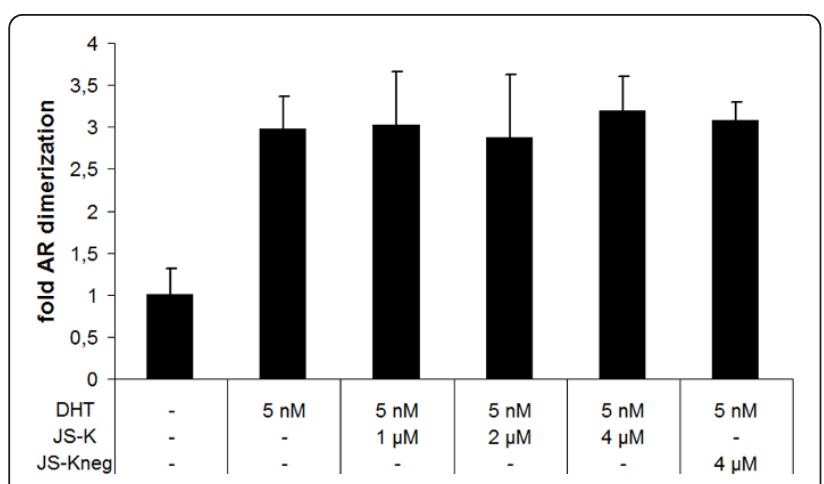

Figure 3 JS-K does not inhibit AR-dimerization in presence of androgens. AR-dimerization was determined in PC-3 cells using the CheckMate Mammalian Two-Hybrid System from Promega as described in Material and Methods. Results are mean values of four independent experiments performed in quadruplicates. point mutation at position 877 (T877A) [39]. Treatment with JS-K for 30 hours diminished the amount of all ARforms in 22Rv1 as well as in LNCaP cells (Figure 5). The downregulation of the AR in LNCaP was less pronounced than the dramatic decrease of AR and AR-V in 22Rv1 cells (Figure 5). In both cell lines incubation with JS-K $\mathrm{K}_{\text {neg }}$ had no influence on intracellular AR-levels (Figure 5).

\section{JS-K inhibits WNT/ $\beta$-catenin signaling in $22 \mathrm{Rv} 1$ cells}

Interaction of the canonical WNT/ $\beta$-Catenin pathway with the AR is thought to promote progression of $\mathrm{PCa}$ to the terminal castrate-resistant stage [40]. Crosstalk between the canonical WNT and AR-pathways occurs at several levels: (a) $\beta$-Catenin interacts with the AR to increase its transcriptional activity [27], (b) WNT-signalling influences AR-signalling through its ability to regulate AR-mRNA as well as AR-stability [41].

Several lines of evidence indicate that $\mathrm{NO}$ is involved in the regulation of the $\mathrm{WNT} / \beta$-catenin pathway in various tumors [42-44]. A common approach to analyze the canonical WNT-pathway in vitro is the over-expression of mutated stabilized $\beta$-catenin (S33Y) that activate TCF/ LEF-dependent reporter gene constructs [27]. As LNCaP cells are unable to activate $\beta$-catenin dependent reporter gene expression [27] we tested the effects of JS-K on the canonical WNT-pathway in $22 \mathrm{Rv} 1$ cells. As seen in Figure 6 , JS-K was able to diminish $\beta$-catenin signalling in the CRPC cell line 22Rv1 in a dose dependent manner. Downregulation of the canonical WNT-pathway was already significant at JS-K concentrations of $1 \mu \mathrm{M}$ (reduction of transcriptional activity: $42 \pm 8 \%, \mathrm{p}<0.01$ ).

\section{Growth inhibitory effects of JS-K are most pronounced in} castration resistant prostate cancer cells

Based on our observations we tested the antiproliferative effects of JS-K on prostate cancer cell lines. JS-K neg $_{\text {served }}$ as negative control. Cellular proliferation was assessed by 

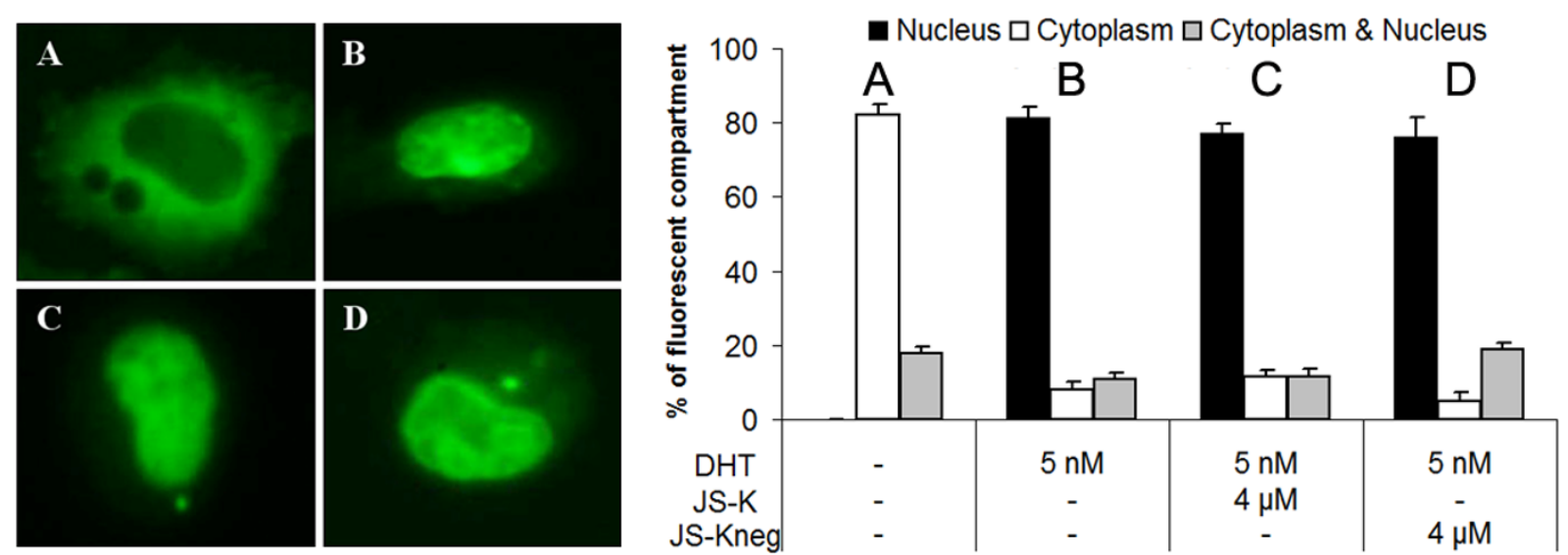

Figure 4 NO does not influence hormone-induced nuclear translocation of the AR. Prostate cancer cells (PC-3) expressing a green fluorescent AR-EosFP [37] were incubated for 6 hours in the absence/presence of DHT and JS-KJJS-Kneg. Intracellular localization of AR-EosFP was determined by fluorescence microscopy: (A) untreated controls, (B) $5 \mathrm{nM} \mathrm{DHT}$, (C) $5 \mathrm{nM}$ DHT and $4 \mu \mathrm{M} J \mathrm{~J}-\mathrm{K}$, (D) $5 \mathrm{nM}$ DHT and $4 \mu \mathrm{M}$ JS$\mathrm{K}_{\text {neg. }}$ Bars: Data presented in \% cellular localization \pm SD. Results are mean values of three independent experiments performed in quadruplicates.

means of a colorimetric MTT assay, measuring the reduction of tetrazolium salts to formazan derivatives by functional mitochondria [32,33]. Although redox sensitive viability assays have some limitations depending on the chemical nature of the compounds to be evaluated [45] they are widely used for measuring cell viability following nitrosative or oxidative stress $[22,46,47]$. The suitability of this method was furthermore documented by a previous study analyzing the effects of the spontaneous NO-donor DETA/NO on the viability of PCa-cells. Comparison of MTT with three commonly used methods to measure cell proliferation, i.e quantification of intracellular ATP, trypan

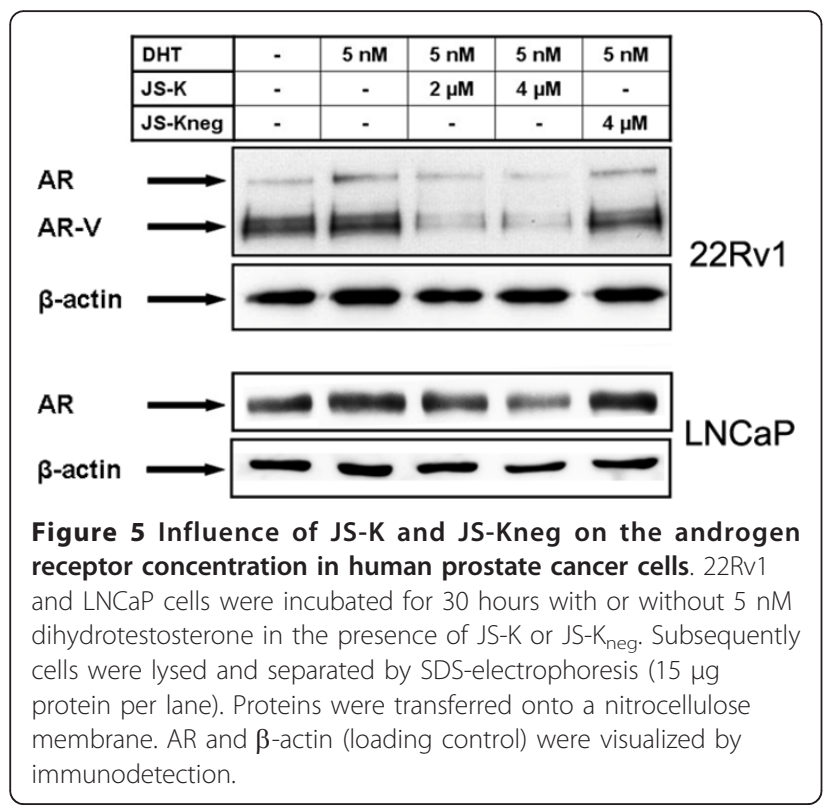

blue dye exclusion and neutral red assay were found to generate similar results [22].

A first series of experiments indicated that castration resistant 22Rv1 cells were more susceptible to the growth inhibitory effects of JS-K than the androgen sensitive LNCaP cells (Figure 7A). Maximal growth inhibitory effects were achieved at a concentration of $4 \mu \mathrm{M}$ JS-K for 22Rv1 (growth inhibition $50 \pm 6 \%, \mathrm{p}<0.05$ ) and $4 \mu \mathrm{M}$ JS-K for LNCaP (growth inhibition $23 \pm 9 \%$ ).

Given the highly divergent nature of the AR-positive cell lines 22Rv1 and LNCaP we repeated the proliferation experiments using the androgen sensitive $\mathrm{LNCaP}$ and LNCaP-SSR, an AR-positive castration resistant LNCaPsubline. The AR-negative DU-145 served as control (AR

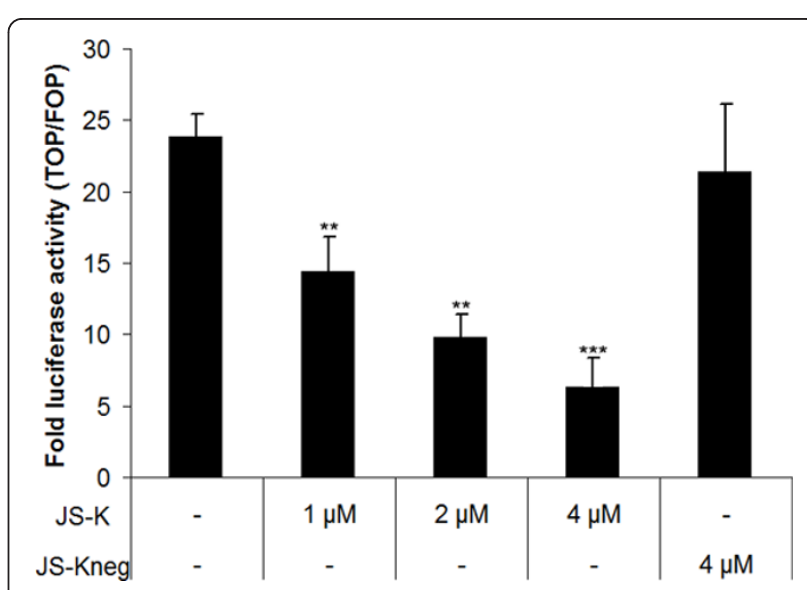

Figure 6 JS-K diminishes WNT-signalling in 22Rv1 cells. 22Rv1 cells were co-transfected with an expression vector for mutated, stabilized $\beta$-catenin together with either the TCF reporter construct TOP or FOP as recently described [25]. Data are presented as fold of untreated controls (TOP/FOP) $\pm S D,{ }^{* *} p<0.01,{ }^{* * *} p<0.001$. 


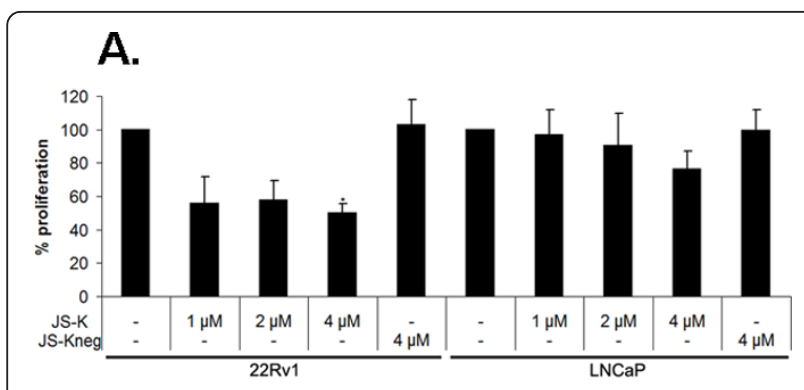

B.

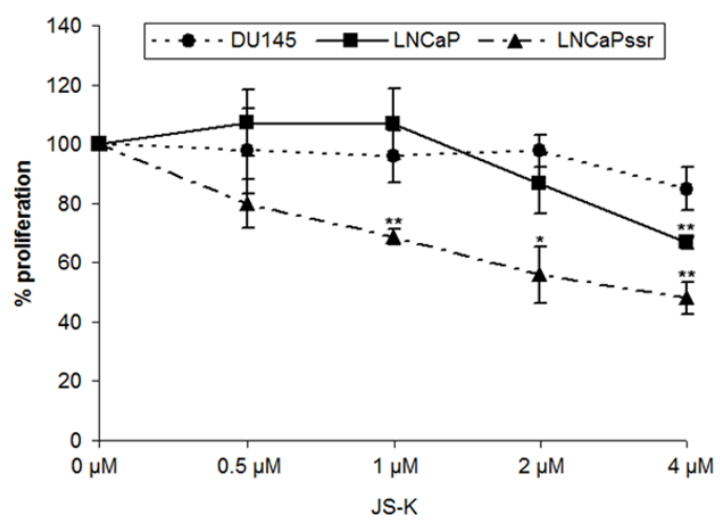

Figure 7 Effects of JS-K on the proliferation of prostate cancer cells. (A) 22Rv1 cells are more susceptible to the growth inhibitory effects of JS-K than the androgen sensitive LNCaP cells Cells were cultured in the absence/presence of increasing concentrations of JS$\mathrm{K}(1,2,4 \mu \mathrm{M})$ or JS-K $\mathrm{K}_{\text {neg }}(4 \mu \mathrm{M})$. Cell viability was determined after 96 hours by a colorimetric MTT assay. Results are mean values of four independent experiments performed in quadruplicates. Data are presented as $\%$ of untreated controls $\pm S D,{ }^{*} p<0.05$. (B) Effects of JS-K on the AR negative DU-145 and the AR-positive LNCaP (hormone sensitive) and LNCaP-SSR (castration resistant). Cells were cultured in the absence/presence of increasing concentrations of JS$\mathrm{K}(1,2,4 \mu \mathrm{M})$ or JS-K $\mathrm{K}_{\text {neg }}(4 \mu \mathrm{M})$. Cell viability was determined after 96 hours by a colorimetric MTT assay. Results are mean values of four independent experiments performed in quadruplicates.

off-target effects). Interestingly, the castration resistant LNCaP-SSR cells were more susceptible to the growth inhibitory effects (growth inhibition at $1 \mu \mathrm{M}$ JS-K $31 \pm$ $2 \%, \mathrm{p}<0.01$ ) than the parental LNCaP cells (growth inhibition at $4 \mu \mathrm{M} J S-K 33 \pm 1 \%, \mathrm{p}<0.01$ ) (Figure $7 \mathrm{~B}$ ). In contrast to the AR-positive LNCaP and LNCaP-SSR the AR-negative DU-145 were less susceptible to the growth inhibitory effects of JS-K (growth inhibition at $4 \mu \mathrm{M}$ JS-K $17 \pm 9 \%)$.

\section{Discussion}

Current treatment for advanced PCa is mainly based on androgen ablation therapies like chemical or surgical castration or application of anti-androgens. Although hormonal therapy is initially very effective, the benefit of androgen withdrawal is only transitory. While still expressing high levels of functional AR, some PCa cells acquire the ability to grow and survive under castrate levels of circulating androgens. The mechanisms involved in an altered AR-signalling of CRPC cells include an over-expression/amplification of the AR (hypersensitive pathway), point mutations broadening ligand-specificity of the receptor (promiscuous pathway) as well as activation of the AR by peptide growth factors or cytokines (outlaw pathway) [17]. A recently identified mechanism enabling CRPC cells to bypass the requirements for physiological levels of androgens is the expression of C-terminal truncated, constitutively active AR splicing variants termed AR-V. Due to the loss of the C-terminus, AR-Vs are lacking essential parts of the ligand binding domain [21]. In the absence of androgens, AR-Vs were shown to induce AR-signalling either as AR-V/AR-V-homodimers or AR-V/AR-heterodimers $[18,48]$. Whereas AR-V/AR-V homodimers are unaffected by hormone ablation in general, some AR-V/AR-heterodimers were insensitive to the commonly used anti-androgens [48]. Given the fact that both, AR wild type as well as AR-V, play a crucial role in a high percentage of CRPC there is an urgent need for an AR-blockade that does not involve the LBD.

Nitric oxide, a free radical gas, has been repeatedly shown to impair the function of nuclear receptors via targeting their cys $_{4}$-type zinc fingers, located in the DBD of these receptors [49]. This is well exemplified by studies showing a NO-induced nitrosation of the cystein residues within the zinc finger structures of steroid receptors like the estrogen receptor (ER) [50]. As the DBD is a crucial part of functional full length AR as well as constitutively active AR-Vs, it is tempting to speculate that NO-donors able to release $\mathrm{NO}$ in a spatial and timely controllable manner could be of special interest for the treatment of deregulated AR-signalling in CRPC cells.

Inhibitory effects of NO on AR-function in PCa cells was first described in vitro using the spontaneous NOdonor Deta/NO [22]. In a recent clinical study Siemens et al. were able to show an increase of the PSA doubling time in patients treated with the NO-donor glyceryl trinitrate (GTN) [51]. No cardiovascular toxicities or serious side effects were encountered during treatment with GTN [51]. Although the number of patients enrolled in the study was relatively low (29 patients), our data and the clinical data with GTN [22,51] support the assumption that $\mathrm{NO}$ might be suitable for the treatment of advanced PCa.

Commonly used NO-Donors like Deta/NO, spontaneously dissociate in a $\mathrm{pH}$ dependent process thereby releasing the free radical NO. Unfortunately NO exhibits only a relatively short half-life in the tissue culture medium or body fluids. Therefore, we tested a potent NOprodrug, the non-ionic nitroaromatic diazeniumdiolate 
JS-K. The compound was shown to be activated by glutathione S-transferase (GST), a key phase II detoxification enzyme that is frequently over-expressed in cancer tissue. Among the various isoforms of GSTs which are located in the cytoplasm and the mitochondria, mainly the $\pi$ isoform is able to form the so called $<$ Meisenheimer complex $>$ [52] which finally delivers NO directly within the cell. First experimental in vivo studies using tumor xenografts in a mouse model, showed that JS-K exhibits a strong anti-tumor activity and is generally well tolerated by the host organism [5,23,24].

In order to test the effects of JS-K on AR signalling, we treated the AR-positive CRPC cell line 22Rv1 grown in presence of DHT with increasing concentrations of JS-K. Generation of intracellular NO was monitored indirectly by detection of nitrotyrosine using fluorescence microscopy. JS-K was able to inhibit the genomic functions of the AR in $22 \mathrm{Rv} 1$ cells. The inhibition of AR-signalling was neither due to an inhibition of AR-dimerization nor to an inhibition of nuclear translocation. Interestingly, JS-K was able to diminish intracellular levels of all AR-isoforms in PCa cells. However, in contrast to the dramatic downregulation of AR-V and AR in 22Rv1 cells the intracellular AR levels of LNCaP were only slightly affected.

So far, studies on intracellular steroid receptor levels following NO-treatment are sparse. In a previous study using Deta/NO as an NO-donor the concentration of the endogenous $\mathrm{AR}$ in $\mathrm{LNCaP}$ remained unaffected [22]. In contrast, DETA/NO was able to downregulate the intracellular levels of the Drosophila melanogaster ecdysteroid receptor $(\mathrm{EcR})$ when overexpressed in chinese hamster ovary cells, CHO-K1 [53]. Although the heterologeous expression of an insect steroid receptor in $\mathrm{CHO}-\mathrm{K} 1$ cells differs largely from the situation found in LNCaP cells that express high levels of intracellular AR under physiological conditions the present data suggest that there are cell specific differences in the sensitivity of cells towards NO-treatment. Moreover, the generation of NO by JS-K largely depends on the intracellular GST-activity that differs between different cell lines or cell types.

The fact that NO is able to inhibit the canonical WNTpathway in different tumor cells [42-44] including prostate cancer cells (as seen in this study) offers a more intriguing explanation for the massive down regulation of $A R$ and AR-V in 22Rv1 cells. There is experimental evidence that the WNT/ $\beta$-catenin-pathway is able to upregulate AR-mRNA expression in prostate cancer cell lines through interaction with TCF/LEF binding sites situated in the promoter region of the AR [41]. In contrast to the highly aggressive castration resistant 22Rv1 cells which are able to drive a WNT-typical T-cell factor (TCF)-dependent reporter gene activity, the androgen sensitive LNCaP are unable to do so [27]. In consequence, the inhibition of the canonical WNT-pathway would lead to a decrease of AR and AR-V mRNA in 22Rv1 cells but not or to a lesser extent in LNCaP.

In proliferation assays castration resistant $22 \mathrm{Rv} 1$ and LNCaP-SSR cells were more susceptible to the growth inhibitory effects of JS-K than LNCaP. Whereas LNCaP cells largely depend on androgenic stimuli, the 22Rv1 and LNCaP-SSR cells are able to grow under androgen deprived conditions. LNCaP cells express a full length AR with a point mutation at position 877 (T877A), enabling the AR to be stimulated by different steroids (promiscuous AR) [39]. In contrast to the hormone dependent LNCaP, the castration resistant LNCaP-SSR cells were shown to exhibit high levels of nuclear AR in the absence of hormonal stimuli [26]. Increased nuclear AR-levels were paralleled by elevated PSA-levels suggesting that the $A R$ is active in these cells [26]. In 22Rv1 cells two AR-forms can be found: A larger ARform expressing 3 zinc finger motifs due to the duplication of exon 3 ( $\mathrm{AR}^{\mathrm{Ex} 3 \mathrm{dup}}$ ) and a C-terminally truncated, constitutively active AR-V [20]. In the absence of androgenic stimuli, some AR-Vs have been shown to form constitutively active AR-V-homodimers or AR/AR-Vheterodimers, thereby uncoupling the need of CRPC cells for physiological levels of androgens $[18,48]$. Although it is unknown whether $\mathrm{AR}^{\mathrm{Ex} 3 \mathrm{dup}}$ is able to form androgen independent heterodimers with AR-V in $22 \mathrm{Rv} 1$ cells, its expression of 3 zinc finger structures makes it probably also more susceptible to the effects of NO. The fact that NO targets the zinc finger structures of wild type AR, mutated AR-forms as well as AR-Vs suggests that NO-donors are promising compounds for the treatment of deregulated AR-activity. Moreover, the observation that CRPC cells like 22Rv1 or LNCaP-SSR, expressing either constitutively active AR-Vs or functionally deregulated full length AR, are more susceptible to the effects of JS-K than LNCaP cells further supports this assumption.

\section{Conclusions}

From our in vitro studies we conclude that GST-activated NO-prodrugs like JS-K show features which might be suited for the treatment of advanced PCa. Therapies targeting the AR and the canonical WNT pathway may lead to a more efficient treatment of CRPC. Therefore, compounds like JS-K may serve as leader compounds for the development of NO-based therapeuticals, targeting key structures in castration resistant prostate cancer cells.

\section{Additional material}

Additional file 1: Figure 1S: JS-K does not inhibit AR-dimerization

Complementary data to experiment presented in Figure 3: AR-

dimerization was determined in DU-145 cells using the CheckMate 
Mammalian Two-Hybrid System described in Material and Methods. Results are mean values of three independent experiments performed in quadruplicates. (DOC $20 \mathrm{~kb}$ ).

Additional file 2: Figure 2S: NO does not influence hormoneinduced nuclear translocation of AR-EosFP in DU-145.

Complementary data to experiment presented in Figure 4. (TIFF $1541 \mathrm{~kb}$ ).

\section{Acknowledgements}

This work was supported by grants from the Deutsche

Forschungsgemeinschaft (HE 6078), Action Lions Vaincre le Cancer, Luxembourg (MVC) and the International Graduate School in Molecular Medicine UIm (ML). The authors thank K. Dengler-Wupperfeld and S. Schmidt for skillful technical assistance.

\section{Author details}

Institute for General Zoology and Endocrinology, Ulm University, Albert Einstein Allee 23, 89069 Ulm, Germany. ${ }^{2}$ Department of Urology, Ulm University, Prittwitzstrasse 43, 89075, Ulm, Germany.

\section{Authors' contributions}

ML, K-D S and MVC conceived the study; ML, WS, AH performed the experiments, MS AJS contributed to data analysis; MVC, K-D S, AJS, MS wrote the paper. All authors read and approved the final manuscript.

\section{Competing interests}

The authors declare that they have no competing interests.

Received: 4 November 2011 Accepted: 30 March 2012

Published: 30 March 2012

\section{References}

1. Burgaud JL, Riffaud JP, Del Soldato P: Nitric-oxide releasing molecules: A new class of drugs with several major indications. Curr Pharm Design 2002, 8:201-213.

2. Pavlos $\mathrm{CM}, \mathrm{Xu}$, Toscano JP: Photosensitive precursors to nitric oxide. Curr Top Med Chem 2005, 5:637-647.

3. Kanwar JR, Kanwar RK, Burrow H, Baratchi S: Recent advances on the roles of NO in cancer and chronic inflammatory disorders. Curr Med Chem 2009, 16:2373-2394.

4. Ahmad R, Rasheed Z, Ahsan H: Biochemical and cellular toxicology of peroxynitrite: implications in cell death and autoimmune phenomenon. Immunopharmacol Immunotoxicol 2009, 31:388-396.

5. Kiziltepe T, Anderson KC, Kutok JL, Jia L, Boucher KM, Saavedra JE, Keefer LK, Shami PJ: JS-K has potent anti-angiogenic activity in vitro and inhibits tumour angiogenesis in a multiple myeloma model in vivo. $J$ Pharm Pharmacol 2010, 62:145-151.

6. McMurtry V, Saavedra JE, Nieves-Alicea R, Simeone AM, Keefer LK, Tari AM: $J S-K$, a nitric oxide-releasing prodrug, induces breast cancer cell death while sparing normal mammary epithelial cells. Int J Oncol 2011, 38:963-971.

7. Cantuaria G, Magalhaes A, Angioli R, Mendez L, Mirhashemi R, Wang J, Wang P, Penalver M, Averette $H$, Braunschweiger P: Antitumor activity of a novel glyco-nitric oxide conjugate in ovarian carcinoma. Cancer 2000, 88:381-388.

8. Stevens EV, Carpenter AW, Shin JH, Liu J, Der CJ, Schoenfisch MH: Nitric oxide-releasing silica nanoparticle inhibition of ovarian cancer cell growth. Mol Pharm 2010, 7:775-785.

9. Sugita H, Kaneki M, Furuhashi S, Hirota M, Takamori H, Baba H: Nitric oxide inhibits the proliferation and invasion of pancreatic cancer cells through degradation of insulin receptor substrate-1 protein. Mol Cancer Res 2010, 8:1152-1163.

10. Royle JS, Ross JA, Ansell I, Bollina P, Tulloch DN, Habib FK: Nitric oxide donating nonsteroidal anti-inflammatory drugs induce apoptosis in human prostate cancer cell systems and human prostatic stroma via caspase-3. J Urol 2004, 172:338-344

11. Huguenin S, Fleury-Feith J, Kheuang L, Jaurand MC, Bolla M, Riffaud JP, Chopin DK, Vacherot F: Nitrosulindac (NCX 1102): a new nitric oxidedonating non-steroidal anti-inflammatory drug (NO-NSAID), inhibits proliferation and induces apoptosis in human prostatic epithelial cell lines. Prostate 2004, 61:132-141.

12. Jemal A, Siegel R, Xu J, Ward E: Cancer Statistics. CA Cancer J Clin 2010 60:277-300.

13. Kirby M, Hirst C, Crawford ED: Characterising the castration-resistant prostate cancer population: a systematic review. Int J Clin Pract 2011, 65:1180-1192.

14. Visakorpi T, Hyytinen E, Koivisto P, Tanner M, Keinänen R, Palmberg C, Palotie A, Tammela T, Isola J, Kallioniemi OP: In vivo amplification of the androgen receptor gene and progression of human prostate cancer. Nat Genet 1995, 9:401-406.

15. Hobisch Z, Culig C, Radmayr G, Bartsch H, Klocker A, Hittmair A: Distant metastases from prostatic carcinoma express androgen receptor protein. Cancer Res 1995, 55:3068-3072.

16. Hobisch A, Culig Z, Radmayr C, Bartsch G, Klocker H, Hittmair A: Androgen receptor status of lymph node metastases from prostate cancer. Prostate 1996, 28:129-135.

17. Cronauer MV, Schulz WA, Burchardt T, Anastasiadis AG, de la Taille A, Ackermann $\mathrm{R}$, Burchardt $\mathrm{M}$ : The androgen receptor in hormone-refractory prostate cancer: relevance of different mechanisms of androgen receptor signaling (Review). Int J Oncol 2003, 23:1095-1102.

18. Céraline J, Cruchant MD, Erdmann E, Erbs P, Kurtz JE, Duclos B, Jacamin D, Chopin D, Bergerat JP: Constitutive activation of the androgen receptor by a point mutation in the hinge region: A new mechanism for androgen-independent growth in prostate cancer. Int J Cancer 2004, 108:152-157.

19. Libertini SJ, Tepper CG, Rodriguez V, Asmuth DM, Kung HJ, Mudryj M: Evidence for calpain-mediated androgen receptor cleavage as a mechanism for androgen independence. Cancer Res 2007, 67:9001-9005.

20. Dehm SM, Schmidt LJ, Heemers HV, Vessella RL, Tindall DJ: Splicing of a novel androgen receptor exon generates a constitutively active androgen receptor that mediates prostate cancer therapy resistance. Cancer Res 2008, 68:5469-5477.

21. Dehm SM, Tindall DJ: Alternatively spliced androgen receptor variants. Endocr Relat Cancer 2011, 18:R183-R196.

22. Cronauer MV, Ince $Y$, Engers $R$, Rinnab L, Weidemann W, Suschek CV, Burchardt M, Kleinert H, Wiedenmann J, Sies H, Ackermann R, Kröncke KD: Nitric oxide-mediated inhibition of androgen receptor activity: possible implications for prostate cancer progression. Oncogene 2007, 26:1875-1884.

23. Shami PJ, Saavedra JE, Wang $L Y$, Bonifant $C L$, Diwan BA, Singh SV, Gu Y, Fox SD, Buzard GS, Citro ML, Waterhouse DJ, Davies KM, Ji X, Keefer LK: JS$\mathrm{K}$, a glutathione/glutathione S-transferase-activated nitric oxide donor of the diazeniumdiolate class with potent antineoplastic activity. $\mathrm{Mol}$ Cancer Ther 2003, 2:409-417.

24. Kiziltepe T, Hideshima T, Ishitsuka K, Ocio EM, Raje N, Catley L, Li CQ, Trudel LJ, Yasui H, Vallet S, Kutok JL, Chauhan D, Mitsiades CS, Saavedra JE, Wogan GN, Keefer LK, Shami PJ, Anderson KC: JS-K, a GST-activated nitric oxide generator, induces DNA double-strand breaks, activates DNA damage response pathways, and induces apoptosis in vitro and in vivo in human multiple myeloma cells. Blood 2007, 110:709-718.

25. Chen MW, Vacherot F, De La Taille A, Gil-Diez-De-Medina S, Shen R, Friedman RA, Burchardt M, Chopin DK, Buttyan R: The emergence of protocadherin-PC expression during the acquisition of apoptosisresistance by prostate cancer cells. Oncogene 2002, 21:7861-7871.

26. Schütz SV, Schrader AJ, Zengerling F, Genze F, Cronauer MV, Schrader M: Inhibition of glycogen synthase kinase- $3 \beta$ counteracts ligandindependent activity of the androgen receptor in castration resistant prostate cancer. PLoS One 2011, 6:e25341.

27. Cronauer MV, Schulz WA, Ackermann R, Burchardt M: Effects of WNT/ $\beta$ catenin pathway activation on signaling through T-cell factor and androgen receptor in prostate cancer cell lines. Int J Oncology 2005 26:1033-1040.

28. Laschak M, Bechtel M, Spindler KD, Hessenauer A: Inability of NCoR/SMRT to repress androgen receptor transcriptional activity in prostate cancer cell lines. Int J Mol Med 2011, 28:645-651.

29. Rinnab L, Schütz SV, Jeannine Diesch J, Schmid E, Küfer R, Hautmann RE, Spindler K-D, Cronauer MV: Inhibiton of Glycogen-Synthase Kinase-3 (GSK) in Androgen Responsive Prostate Cancer Cell Lines - Are GSKInhibitors Therapeutically Useful? Neoplasia 2008, 10:624-634. 
30. Schneider CC, Hessenauer A, Montenarh M, Götz C: p53 is dispensable for the induction of apoptosis after inhibition of protein konase CK2. Prostate 2010, 70:126-134.

31. Green LC, Wagner DA, Glogowski J, Skipper PL, Wishnok JS, Tannenbaum SR: Analysis of nitrate, nitrite, and [15 N]nitrate in biological fluids. Anal Biochem 1982, 126:131-138.

32. Mosmann T: Rapid colorimetric assay for cellular growth and survival: application to proliferation and cytotoxicity assays. J Immunol Methods 1983, 65:55-63.

33. Park JG, Kramer BS, Steinberg SM, Carmichael J, Collins JM, Minna JD, Gazdar AF: Chemosensitivity testing of human colorectal carcinoma cell lines using a tetrazolium-based colorimetric assay. Cancer Res 1987, 47:5875-5879.

34. Mazur W, Gonciarz M, Kajdy M, Mazurek U, Jurzak M, Wilczok T, Gonciarz Z: Blood serum glutathione alpha s-transferase (alpha GST) activity during antiviral therapy in patients with chronic hepatitis C. Med Sci Monit 2003, 9(Suppl 3):44-48.

35. Habdous M, Vincent-Viry M, Visvikis S, Siest G: Rapid spectrophotometric method for serum glutathione S-transferases activity. Clin Chim Acta 2002, 326:131-142

36. Kröncke $\mathrm{KD}$, Carlberg C: Inactivation of zinc finger transcription factors provides a mechanism for a gene regulatory role of nitric oxide. FASEB $J$ 2000, 14:166-173.

37. Wiedenmann J, Ivanchenko S, Oswald F, Schmitt F, Röcker C, Salih A, Spindler K-D, Nienhaus GU: EosFP, a fluorescent marker protein with UVinducible green-to-red fluorescence conversion. Proc Natl Acad Sci USA 2004, 101:15905-15910.

38. Tepper CG, Boucher DL, Ryan PE, Ma AH, Xia L, Lee LF, Pretlow TG, Kung $\mathrm{HJ}$ : Characterization of a novel androgen receptor mutation in a relapsed CWR22 prostate cancer xenograft and cell line. Cancer Res 2002, 62:6606-6614.

39. Tan J, Sharief Y, Hamil KG, Gregory CW, Zang DY, Sar M, Gumerlock PH, DeVere White RW, Pretlow TG, Harris SE, Wilson EM, Mohler JL, French FS: Dehydroepiandrosterone activates mutant androgen receptors expressed in the androgen-dependent human prostate cancer xenograft CWR22 and LNCaP cells. Mol Endocrinol 1997, 11:450-459.

40. Wang G, Wang J, Sadar MD: Crosstalk between the androgen receptor and beta-catenin in castrate-resistant prostate cancer. Cancer Res 2008, 68:9918-9927.

41. Yang X, Chen MW, Terry S, Vacherot F, Bemis DL, Capodice J, Kitajewski J, de la Taille A, Benson MC, Guo Y, Buttyan R: Complex regulation of human androgen receptor expression by Wnt signaling in prostate cancer cells. Oncogene 2006, 25:3436-3444.

42. Prévotat L, Filomenko R, Solary E, Jeannin JF, Bettaieb A: Nitric oxideinduced down-regulation of beta-catenin in colon cancer cells by a proteasome-independent specific pathway. Gastroenterology 2006, 131:1142-1152.

43. Nath N, Vassell R, Chattopadhyay M, Kogan M, Kashfi K: Nitro-aspirin inhibits MCF-7 breast cancer cell growth: effects on COX-2 expression and Wnt/beta-catenin/TCF-4 signaling. Biochem Pharmacol 2009, 78:1298-1304.

44. Nath N, Chattopadhyay M, Pospishil L, Cieciura LZ, Goswami S, Kodela R, Saavedra JE, Keefer LK, Kashfi K: JS-K, a nitric oxide-releasing prodrug, modulates $\beta$-catenin/TCF signaling in leukemic Jurkat cells: evidence of an S-nitrosylated mechanism. Biochem Pharmacol 2010, 80:1641-1649.

45. Wang P, Henning SM, Heber D: Limitations of MTT and MTS-based assays for measurement of antiproliferative activity of green tea polyphenols. PLoS One 2010, 5:e10202.

46. Tiedge M, Lortz S, Munday R, Lenzen S: Protection against the cooperative toxicity of nitric oxide and oxygen free radicals by overexpression of antioxidant enzymes in bioengineered insulinproducing RINm5F cells. Diabetologia 1999, 42:849-855.

47. Royle JS, Ross JA, Ansell I, Bollina P, Tulloch DN, Habib FK: Nitric oxide donating nonsteroidal anti-inflammatory drugs induce apoptosis in human prostate cancer cell systems and human prostatic stroma via caspase-3. J Urol 2004, 172:338-344.

48. Watson PA, Chen YF, Balbas MD, Wongvipat J, Socci ND, Viale A, Kim K, Sawyers CL: Constitutively active androgen receptor splice variants expressed in castration-resistant prostate cancer require full-length androgen receptor. Proc Natl Acad Sci USA 2010, 107:16759-16765.
49. Spindler K-D, Laschak M, Cronauer MV: Nitric oxide - a tool to block nuclear receptors. In Nuclear Receptors. Edited by: Bates MK, Kerr RM. New York: Nova Science Publishers Inc; 2011:87-102.

50. Garbán HJ, Márquez-Garbán DC, Pietras RJ, Ignarro LJ: Rapid nitric oxidemediated S-nitrosylation of estrogen receptor: regulation of estrogendependent gene transcription. Proc Natl Acad Sci USA 2005, 102:2632-2636.

51. Siemens DR, Heaton JP, Adams MA, Kawakami J, Graham CH: Phase II study of nitric oxide donor for men with increasing prostate-specific antigen level after surgery or radiotherapy for prostate cancer. Urology 2009, 74:878-883.

52. Bico P, Chen CY, Jones M, Erhardt J, Dirr H: Class pi glutathione Stransferase: Meisenheimer complex formation. Biochem Mol Biol Int 1994, 33:887-892.

53. Cronauer MV, Braun S, Tremmel Ch, Kröncke KD, Spindler-Barth M: Nuclear localization and DNA binding of ecdysone receptor and ultraspiracle. Arch Insect Biochem Physiol 2007, 65:125-133

\section{Pre-publication history}

The pre-publication history for this paper can be accessed here: http://www.biomedcentral.com/1471-2407/12/130/prepub

doi:10.1186/1471-2407-12-130

Cite this article as: Laschak et al:: JS-K, a glutathione/glutathione Stransferase-activated nitric oxide releasing prodrug inhibits androgen receptor and WNT-signaling in prostate cancer cells. BMC Cancer 2012 12:130.

\section{Submit your next manuscript to BioMed Central and take full advantage of:}

- Convenient online submission

- Thorough peer review

- No space constraints or color figure charges

- Immediate publication on acceptance

- Inclusion in PubMed, CAS, Scopus and Google Scholar

- Research which is freely available for redistribution 